\title{
Effect of Process Parameters and Kraft Lignin Additive on The Mechanical Properties of Miscanthus Pellets ${ }^{1}$
}

\author{
Chang Ha Min² B Byung Hwan Um (D) ${ }^{2, \dagger}$
}

\begin{abstract}
Miscanthus had a higher lignin content (19.5 wt\%) and carbohydrate (67.6 wt\%) than other herbaceous crops, resulting in higher pellet strength and positive effect on combustion. However, miscanthus also contains a high amount of hydrophobic waxes on its outer surface, cuticula, which limits the pellet quality. The glass transition of lignin and cuticula were related to forming inter-particle bonding, which determined mechanical properties of pellet. To determine the effects of surface waxes, both on the pelletizing process and the pellet strength were compared with raw and extracted samples through solvent extraction. In addition, to clarify the relationship between pellet process parameters and bonding mechanisms, the particle size and temperature are varied while maintaining the moisture content of the materials and the die pressure at constant values. Furthermore, kraft lignin was employed to determine the effect of kraft lignin as an additive in the pellets. As results, the removal of cuticula through ethanol extractions improved the mechanical properties of the pellet by the formation of strong inter-particle interactions. Interestingly, the presence of lignin in miscanthus improves its mechanical properties and decreases friction against the inner die at temperatures above the glass transition temperature $\left(\mathrm{T}_{\mathrm{g}}\right)$ of lignin. Consequently, it could found that the use of kraft lignin as an additive in pellet reduced friction in the inner die upon reaching its glass transition temperature.
\end{abstract}

Keywords : biomass, miscanthus, pellet, kraft lignin, solid fuel

\section{INTRODUCTION}

As a possible solution to the issue of greenhouse gas emissions from fossil fuels, and more specifically carbon dioxide emissions, the use of biomass is becoming increasingly important. However, in terms of heat and power production, biomass has limits due to its low bulk density, which increases the transportation and storage costs in comparison to fossil fuels (Rentizelas et al., 2009). Thus, the densification of biomass in the form of pellets has a number of economic benefits, and has led to an increase in the global production of wood pellets. However, the use of wood residues and sawdust in pellet manufacture increases the price of

1 Date Received July 4, 2017, Date Accepted August 20, 2017

2 Department of Chemical Engineering and Research Center of Chemical Technology Hankyong National University, Anseong, Gyeonggi-do 17579, Republic of Korea

† Corresponding author: Byung Hwan Um (e-mail: bhum11@hknu.ac.kr, ORCID: 0000-0002-2948-1077) 
these raw materials (Sikkema et al., 2010; Park et al., 2013). Furthermore, the use of energy crops as raw materials increased as the market prices for pellets by $\sim 45 \%$ between 1997 and 2006 (Nilsson et al., 2011), and the import price of wood pellets has gradually increased in line with the increasing price of raw materials. Thus, to stabilize the supply of energy crops in South Korea, Miscanthus sacchariflorus "Goedae-Uksae1," otherwise known as "giant miscanthus," has been developed as an energy crop owing to its impressive yield of 30 ton/ha (Moon et al., 2010) and its higher net energy value and carbohydrate content than that of other energy crops (Brosse et al., 2012; Kaltschmitt et al., 1997).

In general, the mechanical properties of pellets are determined by the temperature and compression pressure at the die and by the particle size and moisture content of the biomass (Mani et al., 2006; Nguyen et al., 2015; Nielsen et al., 2009; Serrano et al., 2011). These factors are closely related to interparticle bonding, which results from the formation of hydrogen bonds between carbohydrates, and the glass transition of lignin (Kaliyan and Morey, 2010). Moreover, because of the lubricating characteristics of lignin, it acts as a natural binder, and is often used as an additive in the form of lignosulfonate, which has been reported to improve the mechanical properties of pellets (Kuokkanen et al., 2011). However, due to the high sulfur content of lignosulfonate, it is not suitable for use in fuel pellets (Vishtal and Kraslawski, 2011). Furthermore, as the cuticula (i.e., the waxy outer coating) of miscanthus consists mainly of hydrophobic components (Villaverde et al., 2009), this has a negative effect on the bonding between biomass particles, and results in a deterioration of the pellet mechanical properties (Stelte et al., 2012).

Thus, we herein chose to investigate the effects of surface waxes on the pelletizing process by comparing miscanthus both before and after solvent extraction. In addition, to clarify the relationship between pellet process parameters and bonding mechanisms, the particle size and temperature are varied while maintaining the moisture content of the materials and the die pressure at constant values. Moreover, to address the issue of defects caused by the high sulfur content of lignosulfonate, kraft lignin derived as a by-product from the kraft pulping process is employed as an additive to the pellets.

\section{MATERIALS and METHODS}

\subsection{Characterization of Miscanthus}

Samples of Miscanthus sacchariflorus "Goedae-Uksae1" (An et al., 2013) were harvested from Sancheong, Kyoengsangnam-do, Korea. Sample particles greater than 10-mesh were removed and classified as 10-mesh (0.841-2.00 mm), 20-mesh (0.491-0.841 mm), and 40-mesh $(<0.491)$ using analytical sieves, and the materials were conditioned at $60-65 \%$ $\mathrm{RH}$ and $25^{\circ} \mathrm{C}$ for $\geq 1$ week.

The chemical composition of miscanthus was 
determined according to the NREL/TP-510-42619 and NREL/TP-510-42618 standard laboratory procedures (Sluiter et al., 2008a; Sluiter et al., 2008b). The ethanol extractives of miscanthus were obtained using an accelerated solvent extractor (ASE-200, Thermo Fisher Scientific Inc., USA) with 190 proof (95\%) ethanol (Sigma-Aldrich, USA) as the solvent.

Fourier transform infrared (FTIR) spectrometry was used to verify the successful removal of the extractives. Spectra were recorded at $30^{\circ} \mathrm{C}$ using a Nicolet iS10 FTIR spectrometer (Thermo Scientific, USA) equipped with a temperature-adjustable attenuated total reflectance (ATR) accessory (Smart MIRacle $^{\mathrm{TM}}$ Single Reflection ATR, PIKE Technologies, USA). The raw and extracted samples were dried at $105^{\circ} \mathrm{C}$ for $24 \mathrm{~h}$ to prevent the interference from moisture during analysis, and the dried samples were stored in sealed containers prior to testing. All spectra were obtained using 200 background scans and 200 sample scans at $4 \mathrm{~cm}^{-1}$ resolution between 650 and $4000 \mathrm{~cm}^{-1}$.

\subsection{Material Pretreatment}

The cuticula were extracted using an accelerated solvent extractor (ASE-200, Thermo Fisher Scientific Inc., USA) with 190 proof (95\%) ethanol (Sigma-Aldrich, USA) as the solvent. After extraction, the samples were dried under ambient conditions to allow solvent evaporation to take place. The dried samples were then conditioned at $60-65 \% \mathrm{RH}$ and $25^{\circ} \mathrm{C}$ for $\geq 1 \mathrm{w}$. Moisture contents were determined using an MA-150 moisture analyzer (Sartorius AG, Germany) to obtain the equilibrium moisture contents of $8.3 \%$ for raw and $8.5 \%$ for the extracted samples.

The kraft black liquor employed herein was supplied by Moorim P\&P Co., Ltd. (Ulsan, Korea). The black liquor samples (200 $\mathrm{m} \ell$, initial $\mathrm{pH}=13$ ) were adjusted to $\mathrm{pH} 0.5$ using 96\% (w/v) sulfuric acid (Sigma-Aldrich, USA). The adjusted samples were stored in $250 \mathrm{~m} \ell$ medium bottles. The autoclave was then heated to $121{ }^{\circ} \mathrm{C}$ for $60 \mathrm{~min}$ at the corresponding vapor pressures. The resulting liquid and solid phases were then separated by vacuum filtration (Buchner funnel equipped with a filter paper). After filtration, the filter paper containing the filter cake was dried at $105^{\circ} \mathrm{C}$ overnight, and the dried lignin was then separated from the filter paper. The recovered lignin sample was then conditioned at $65 \% \mathrm{RH}$ and $25^{\circ} \mathrm{C}$ for 1 week. The equilibrium moisture content at $65 \% \mathrm{RH}$ was $\sim 3.4 \%$.

\subsection{Determination of Glass Transition Temperature}

To determine the glass transition temperature of the cuticula coating, the extracted cuticula was dried on a heating plate at $50^{\circ} \mathrm{C}$ for $2 \mathrm{~h}$, after which time a sample $(5 \mathrm{mg})$ was pressed into an aluminum capsule and analyzed by differential scanning calorimetry (DSC) (DSC7, PerkinElmer, Waltham, MA, USA) between -20 and $100^{\circ} \mathrm{C}$ at a heating rate of $10^{\circ} \mathrm{C} / \mathrm{min}$. The data acquired during the second heating cycle 
was used for interpretation to ensure that good contact was made between the sample pan and the wax, and to remove the previous heat history of the sample (e.g., the data obtained from Soxhlet extraction). The test was run in duplicate and the results were shown to be reproducible.

All materials were conditioned for determining the glass transition temperature of the lignin in raw and extracted samples at $65 \% \mathrm{RH}$ and $25^{\circ} \mathrm{C}$ for $\geq 1$ week. The sample $(10 \mathrm{~g})$ of the conditioned material was molded into a circular disc by pressing between the two steel plates of a pilot scale hot press at $150^{\circ} \mathrm{C}$ and $50 \mathrm{MPa}$ for $5 \mathrm{~min}$. Rectangular specimens $(12.37 \mathrm{~mm}$ length $\times 11.55 \mathrm{~mm}$ width) were cut using a utility knife. The thickness of each specimen ranged from 0.9 to $0.95 \mathrm{~mm}$. The pressed specimens were then conditioned in a climate chamber at $65 \% \mathrm{RH}$ and $25^{\circ} \mathrm{C}$ for $\geq 1$ week. The moisture contents of the samples were determined as described previously. The viscoelastic properties were tested by dynamic mechanical analysis (DMA) (Q8000 DMA, TA-Instruments, New Castle, DE, USA) using a single cantilever grip. After removing the specimens from the climate chamber, their exact dimensions were measured, and they were fixed in the cantilever grip. The samples were subsequently cooled to $-60^{\circ} \mathrm{C}$ using liquid nitrogen. Measurements were conducted between -60 and $200^{\circ} \mathrm{C}$ with amplitude of $5 \mu \mathrm{m}$, a frequency of $1 \mathrm{~Hz}$, and a heating rate of $2{ }^{\circ} \mathrm{C} / \mathrm{min}$. Finally, the storage modulus $\left(\mathrm{E}^{\prime}\right)$ and loss factor $(\tan \delta)$ were used to determine the glass transition tem- peratures of the lignin.

\subsection{Pelletization}

Pellets were individually produced using a single hydraulic pelletizer. The press consisted of a cylindrical die $(7.8 \mathrm{~mm}$ diameter $)$ composed of hardened steel, tagged with heating elements and thermal insulation. The die temperature was adjusted to $30,65,100^{\circ} \mathrm{C}, 135^{\circ} \mathrm{C}$, and the conditioned particles of size 10-mesh, 20-mesh, or 40-mesh ( $1 \mathrm{~g})$ were loaded into the die. These samples were compressed until a maximum pressure of $200 \mathrm{MPa}$ was reached. This pressure was held for $\sim 30 \mathrm{~s}$ prior to release. The backstop was then removed, and the pellet was pushed out of the die.

Samples of lignin additive pellets used a 40-mesh conditioned miscanthus and kraft lignin (1-5 wt $\%, \sim 1 \mathrm{~g})$ as an additive. The die temperature was then adjusted to $30,65,100$, or $135^{\circ} \mathrm{C}$. Prepared samples were loaded into the die and compressed until a maximum pressure of $200 \mathrm{MPa}$ was reached. This pressure was held for $\sim 30 \mathrm{~s}$ prior to release. The backstop was then removed, and the pellet was pushed out of the die.

The maximum force required to press the pellet out of the die was detected by the load cell, and the back pressure was calculated based on the pellet surface area. Finally, the produced pellets were stored at $65 \% \mathrm{RH}$ and $25^{\circ} \mathrm{C}$ in a climate chamber. 


\subsection{Pellet Characterization}

The strength of the manufactured pellets was analyzed by compression testing and determined as the indicated yield point. The conditioned pellets were placed on their side in a compression tester (horizontal compression test method), and were compressed between two metal plates at a rate of $1 \mathrm{~mm} / \mathrm{min}$ until the pellet broke. Compression strength of pellets was calculated by considering yield strength and area of pellet. Strains during the compression test had constant value approximately $1.7 \mathrm{~mm}$. The average force at break and its standard deviation were calculated based on a minimum of five tests per sample. Using a precision balance and caliper, weight and pellet expansion were determined immediately after pressing and after 1 week of conditioning. The obtained values were applied in stereometric measurements (Rabier et al., 2006). Density and expansion data are based on a minimum of five measurements per sample.

\subsection{Surface Analysis}

Scanning electron microscopy (SEM) images (SU-3500, Hitachi Ltd, Japan) were captured for the fractured surfaces of the raw sample and extracted sample pellets. After the above compression test, the pellets were broken into a number of pieces, which were stored at room temperature and under $60-65 \%$ RH until required for testing, at which point the moisture contents of the samples ranged from $8.1 \%$ to

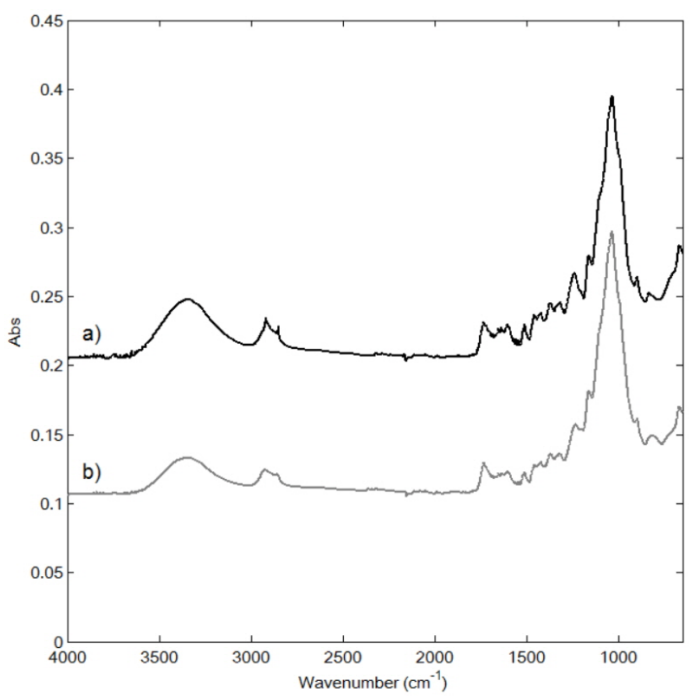

Fig. 1. ATR-FTIR spectra of a) the raw miscanthus, and $b)$ the extracted miscanthus.

$8.4 \%$. A sample was then taken to examine the fractured surface. Prior to recording the SEM images, the samples were attached to a metal stub using conductive carbon tape to prevent movement of the samples during observation. Sputter coating $(0.30 \mathrm{mbar}, 10 \mathrm{~mA}$ coating current) was then employed to coat the samples with palladium and gold using a sputter coater (SU-3500, Hitachi Ltd, Japan). The SEM observation conditions employed were as follows: acceleration voltage $=5 \mathrm{kV}$, distance $=10$ $10.7 \mathrm{~mm}$, magnification $=\times 600$.

\section{RESULTS and DISCUSSION}

\subsection{Chemical Transition after Extraction}

Fig. 1 shows the ATR-FTIR spectra of the raw and extracted samples between 4000 and $650 \mathrm{~cm}^{-1}$. The bands at $3400 \mathrm{~cm}^{-1}(\nu \mathrm{OH})$ and 


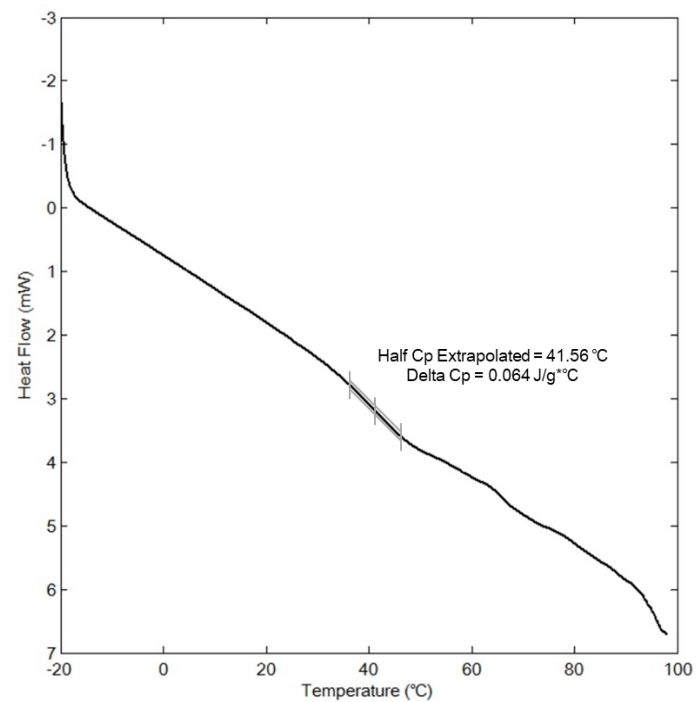

Fig. 2. DSC endothermal plot of the extracted cuticula between 0 and $100^{\circ} \mathrm{C}$.

$1650 \mathrm{~cm}^{-1}\left(\delta_{\mathrm{H}_{2} \mathrm{O}}\right)$ were characteristic for water, while those at 2848 and $2918 \mathrm{~cm}^{-1}$ were assigned to the asymmetric $\left(\nu_{\text {as }}\right)$ and symmetric $\left(\nu_{\mathrm{s}}\right) \mathrm{CH}_{2}$ stretching and methylene rocking $\left(\delta_{\mathrm{CH}_{2}}\right)$ vibrations (Dubis et al., 2001) originating from the cuticula waxes (Merk et al., 1997). In addition, the bands at 1030 and $1504 \mathrm{~cm}^{-1}$ were assigned to the $\mathrm{C}-\mathrm{O}$ stretching vibration in alcohols and aromatic rings and $\mathrm{C}=\mathrm{O}$ stretching, respectively, which are characteristic of cellulose and lignin (Ibarra et al., 2004). The main distinguishing feature of the spectrum after extraction was the transition of the bands at 2848 and $2918 \mathrm{~cm}^{-1}$, confirming the removal of cuticula during extraction. However, because of further peak transition following extraction, the chemical changes could not be verified.
Table 1. Composition of miscanthus

\begin{tabular}{|c|c|}
\hline Component & Weight percent $(\%)$ \\
\hline Glucose & 39.1 \\
\hline Xylose & 27.3 \\
\hline Arabinose & 1.3 \\
\hline Total carbohydrates & 67.6 \\
\hline Lignin & 19.5 \\
\hline Acetate & 1.2 \\
\hline Extractives & 8.2 \\
\hline Total non-carbohydrates & 28.8 \\
\hline Total & 96.5 \\
\hline
\end{tabular}

\subsection{Glass Transition Temperature of the Amorphous Region in Miscanthus}

The various constituents of biomass, such as lignin, cellulose, hemicellulose, and water-soluble carbohydrates, act as natural binders in pellet formation, and can be activated by an increase in the moisture content and temperature (Kaliyan and Morey, 2009). This activation occurs because the increase in the moisture content and temperature result in either melting or glass transition of the biomass binders. As shown in Fig. 2, the glass transition temperature $\left(T_{g}\right)$ of the ethanol extractives was extrapolated from the endothermic plot at $41.5^{\circ} \mathrm{C}$ during DSC analysis. In general, cuticula extracted from the miscanthus surface has a lower $T_{g}$ than that of the majority of other herbaceous crops (Vassilev, 2010).

Fig. 3 shows the DMA spectra of raw (Fig. 3a) and extracted samples (Fig. 3b), which indicate that the storage modulus tends to decrease gradually during the range of glass transition phase. In addition, the $\tan \delta$ response shown in Fig. 3a exhibits two distinct peaks at 

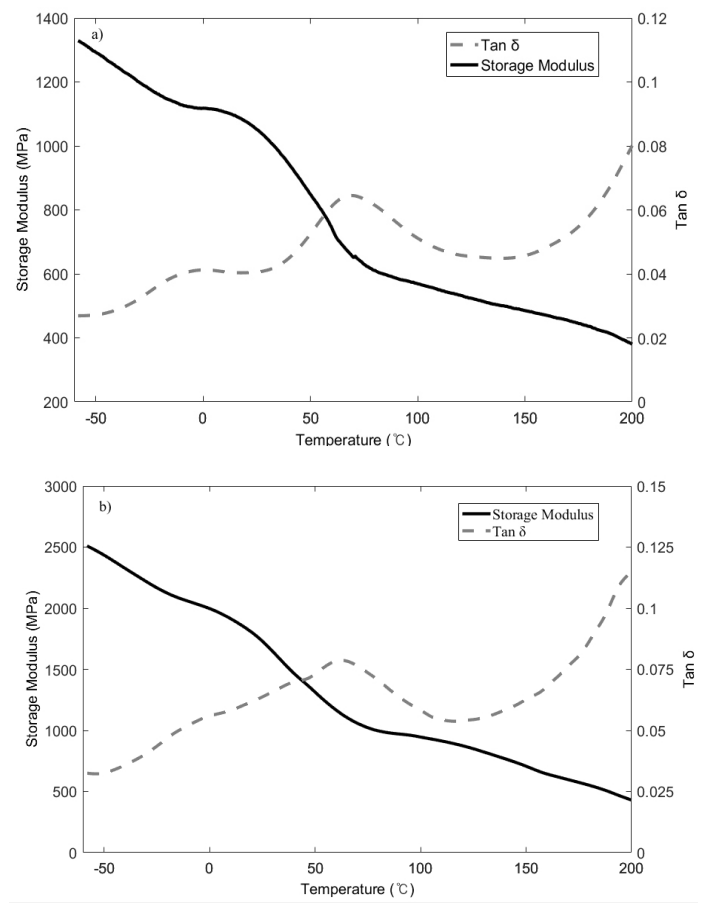

Fig. 3. DMA spectra of a) the raw miscanthus, and b) the extracted miscanthus.

-1.7 and $61.9^{\circ} \mathrm{C}$, while that shown in Fig. $3 \mathrm{~b}$ exhibits two peaks at 0.3 and $65.7^{\circ} \mathrm{C}$. This transition is also common to other herbaceous species and is generally observed in wood, with previous studies demonstrating that straw exhibits similar peaks to wood, which could be attributed to the presence of hemicellulose and lignin (Stelte et al., 2011). After extraction, the observed increase in peak intensity indicates that a chemical transformation took place in the lignin and/or hemicellulose structures. Moreover, because of the diverse composition of lignin among species (Buranov and Mazza, 2008), a range of glass transition temperatures have been reported. However, this phenomenon could not be proved in this study, and there- fore, further studies are required to confirm the chemical or compositional changes taking place in lignin.

\subsection{Effect of Cuticula and Process Parameters on the Pellet Mechanical Properties}

To determine the effect of particle size, die temperature, and removal of cuticula on the miscanthus, we investigated the pelletizing properties of raw and extracted samples for particle sizes of 10-mesh, 20-mesh, and 40-mesh. Temperatures of $30,65,100^{\circ} \mathrm{C}$ and $135 \mathrm{v}$ were employed based on the $\mathrm{T}_{\mathrm{g}}$ values of cuticula (i.e., $41.5^{\circ} \mathrm{C}$ ), lignin-containing raw (i.e., $61.9^{\circ} \mathrm{C}$ ), and extracted sample (i.e., $65.7^{\circ} \mathrm{C}$ ), where it should be considered that the temperature of materials inside the die holes did not reach the maximum values (Serrano et al., 2011). An analysis of regression equations and value of coefficient correlations were suggested Table 2 to describe about relationship between mechanical property parameters and temperature, particle size and extract condition in Fig. 4. It has been previously demonstrated (Nguyen et al., 2015) that during pellet production, the measured friction between materials increases with increasing particle size. Moreover, the injection pressure during the pellet production process constituted a high proportion of the energy usage. For the system of interest here, the friction between the materials during pellet production is outlined in Fig. 4a. In general, for both extracted and raw sample, a larger in- 
Table 2. Regression equations describing about relationship and value of coefficient correlations, $\mathrm{R}^{2}$ between mechanical property parameters and temperature, particle size and extract condition

\begin{tabular}{|c|c|c|c|c|}
\hline Parameter & Particle size & Extract condition & Regression equation & $\mathrm{R}^{2}$ \\
\hline \multirow{6}{*}{ Pressure } & 10 & extract & $\mathrm{P}_{\mathrm{e} 10}=-0.14 \mathrm{~T}+24.22$ & 0.9964 \\
\hline & 10 & raw & $\mathrm{P}_{\mathrm{n} 10}=-0.06 \mathrm{~T}+11.48$ & 0.7819 \\
\hline & 20 & extract & $P_{\mathrm{e} 20}=-0.11 \mathrm{~T}+19.49$ & 0.9965 \\
\hline & 20 & raw & $P_{n 20}=-0.02 T+7.065$ & 0.9975 \\
\hline & 40 & extract & $P_{\mathrm{e} 40}=-0.13 \mathrm{~T}+22.32$ & 0.9972 \\
\hline & 40 & raw & $\mathrm{P}_{\mathrm{n} 40}=-0.04 \mathrm{~T}+8.58$ & 0.9649 \\
\hline \multirow{6}{*}{ Elongation } & 10 & extract & $\mathrm{E}_{\mathrm{e} 10}=2.27 \sin (1.94 \mathrm{~T})+2.65$ & 0.9916 \\
\hline & 10 & raw & $\mathrm{E}_{\mathrm{n} 10}=2.17 \sin (1.94 \mathrm{~T})+2.45$ & 0.9984 \\
\hline & 20 & extract & $\mathrm{E}_{\mathrm{e} 20}=1.96 \sin (1.94 \mathrm{~T})+2.36$ & 0.9827 \\
\hline & 20 & raw & $\mathrm{E}_{\mathrm{n} 20}=3.71 \sin (1.99 \mathrm{~T})+3.96$ & 0.9912 \\
\hline & 40 & extract & $\mathrm{E}_{\mathrm{e} 40}=1.27 \sin (1.94 \mathrm{~T})+1.64$ & 0.9947 \\
\hline & 40 & raw & $\mathrm{E}_{\mathrm{n} 40}=0.99 \sin (1.94 \mathrm{~T})+1.29$ & 0.9981 \\
\hline \multirow{6}{*}{ Density } & 10 & extract & $\mathrm{D}_{\mathrm{e} 10}=196.62 \ln (\mathrm{T})+366.31$ & 0.9999 \\
\hline & 10 & raw & $D_{n 10}=215.01 \ln (T)+235.24$ & 0.9984 \\
\hline & 20 & extract & $\mathrm{D}_{\mathrm{e} 20}=178.95 \ln (\mathrm{T})+475.96$ & 0.9830 \\
\hline & 20 & raw & $\mathrm{D}_{\mathrm{n} 20}=193.78 \ln (\mathrm{T})+344.24$ & 0.9889 \\
\hline & 40 & extract & $\mathrm{D}_{\mathrm{e} 40}=132.69 \ln (\mathrm{T})+704.30$ & 0.9977 \\
\hline & 40 & raw & $\mathrm{D}_{\mathrm{n} 40}=126.40 \ln (\mathrm{T})+672.12$ & 0.9726 \\
\hline \multirow{6}{*}{ Compression strength } & 10 & extract & $\mathrm{C}_{\mathrm{e} 10}=0.07 \mathrm{~T}+1.26$ & 0.9807 \\
\hline & 10 & raw & $\mathrm{C}_{\mathrm{n} 10}=0.03 \mathrm{~T}-0.75$ & 0.9839 \\
\hline & 20 & extract & $\mathrm{C}_{\mathrm{e} 20}=0.06 \mathrm{~T}+3.05$ & 0.9994 \\
\hline & 20 & raw & $\mathrm{C}_{\mathrm{n} 20}=0.03 \mathrm{~T}-0.36$ & 0.9976 \\
\hline & 40 & extract & $\mathrm{C}_{\mathrm{e} 40}=0.09 \mathrm{~T}+4.67$ & 0.9916 \\
\hline & 40 & raw & $\mathrm{C}_{\mathrm{n} 40}=0.05 \mathrm{~T}-0.05$ & 0.9965 \\
\hline
\end{tabular}

jection pressure was required upon increasing the particle size. However, a-1) at 30 and $65^{\circ} \mathrm{C}$, the 10-mesh particles exhibited a greater pressure than both a-2) and a-3), the 20-mesh and 40-mesh samples. This indicates that particle surface area had a greater effect on pressure than particle size. In addition, the results obtained at $135^{\circ} \mathrm{C}$ show that similar pressures were recorded for all sample sizes and extract condition, indicating that the presence of lignin reduces friction inside the die. This is likely due to lignin reaching its $\mathrm{T}_{\mathrm{g}}$ at $61.9-65.7^{\circ} \mathrm{C}$, resulting in melting and subsequent lamination of the particle surface. These factors essentially decrease the friction within the channel. In addition, the increased pressures for the extracted samples compared to the raw samples indicate greater friction for the extracted samples, likely because of the cuticula present on raw samples acting as a lubricant. Moreover, this effect was 

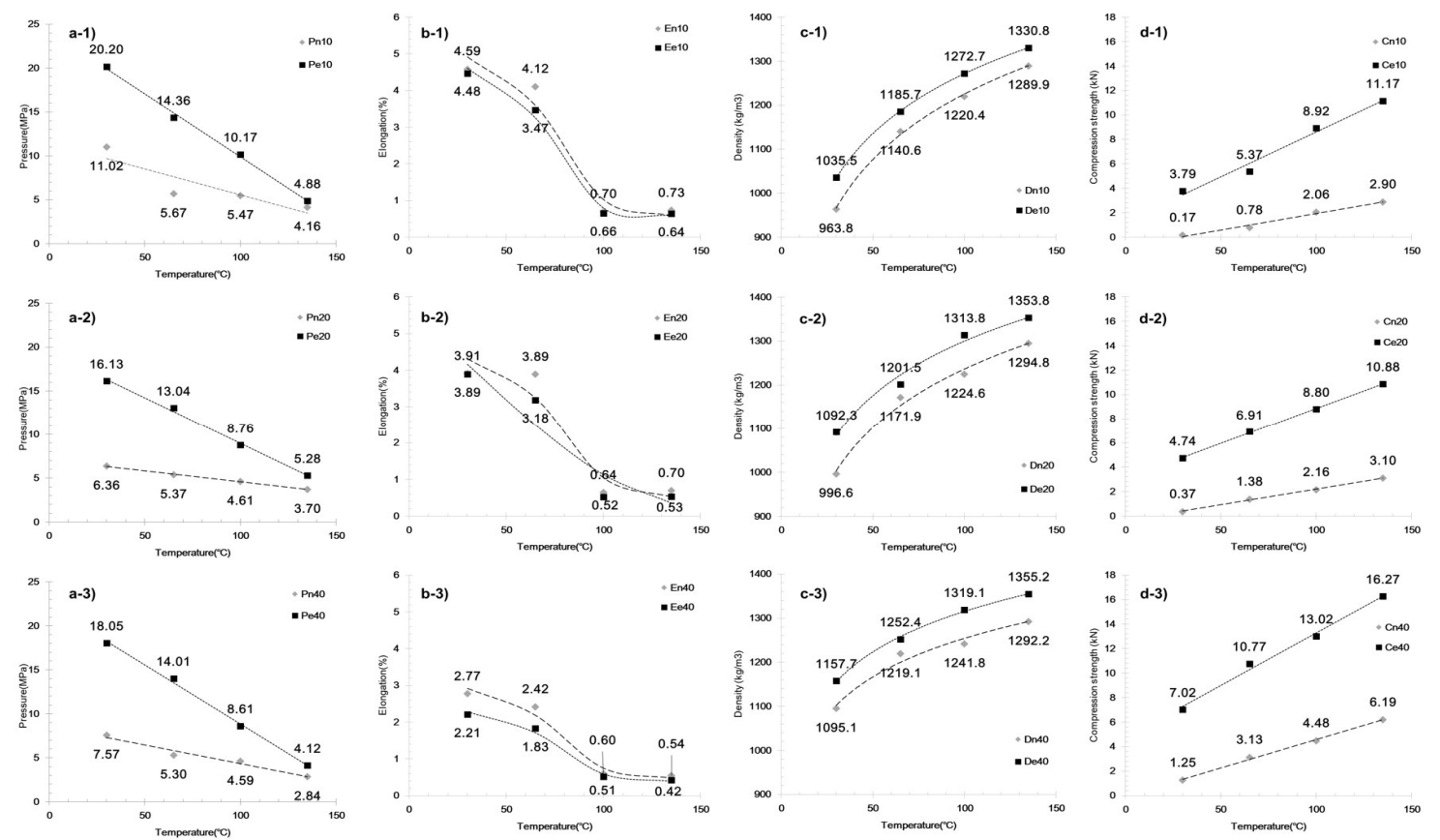

Fig. 4. Effect of particle size, temperature, and extractions on: a) the pressure (Px) required to remove the pellet from the die as an indication of inter-particle friction. b) the elongation after 1 week. c) pellet density after storage for 1 week. d) pellet compression strength represented as the force at break.

enhanced with an increase in temperature, and verifies that both lignin and cuticula act as lubricants in the pellet production.

Fig. 4c shows the effect of temperature, particle size, and extraction on pellet density. This property is of particular importance, as pellet density is used to evaluate the efficiency of a fuel, as fuel efficiency is associated with bulk density that affects the transportation costs. As indicated in the figure c-1) to c-3), pellet density tends to increase with increasing die temperature and particle size, and with the extraction of cuticula, as these factors affect the inter-particle distance and glass transition of the amorphous polymers in miscanthus. For the raw miscanthus sample at $65^{\circ} \mathrm{C}$, elution due to glass transition of the surface cuticula decreases the inter-particle distance, and thus has a greater impact on pellet density than at $30^{\circ} \mathrm{C}$. In addition, at $100^{\circ} \mathrm{C}$, elution resulting from the glass transition of lignin on the inner particles also results in a decrease in the inter-particle distance, thus having a greater impact on the pellet density compared to the effect at $65^{\circ} \mathrm{C}$. In case of sample at $135^{\circ} \mathrm{C}$, increased density was examined. This is interpreted that the almost amorphous region in miscanthus were in glassy transition state which takes effect of increased density. As reported, industrial scale processes tend to produce wood pellets exhibiting [1263 $\mathrm{kg} / \mathrm{m}^{3}$ ] unit density for fine particles $(<1.0$ $\mathrm{mm})$ and $\left[1276 \mathrm{~kg} / \mathrm{m}^{3}\right]$ unit density for coarse 
particles (2.0-4.0 mm) (Tumuluru et al., 2010). Compared to these industrially produced pellets, the raw sample pellets produced in our study at $135^{\circ} \mathrm{C}$ exhibited a lower unit density at all particle sizes examined. However, after cuticula extraction, a higher unit density of 1272-1355 $\mathrm{kg} / \mathrm{m}^{3}$ was obtained for all particle sizes at $135^{\circ} \mathrm{C}$, which is superior to the reported density of the industrial wood pellets. This indicate that cuticula in miscanthus is increasing factor of inter-particle distance.

Figs. $4 \mathrm{~b}$ and $4 \mathrm{~d}$ show the effect of temperature, particle size, and extraction on elongation and compression force (i.e., force at break) of the pellet after 1 week. The variation in elongation and compression forces tends to indicate the effect of inter-particle distance, with elongation decreasing with decreasing particle size, increasing die temperature, and following extraction. The opposite tendencies, however, tend to be observed for the compression force. This phenomenon therefore explains the decrease in the inter-particle distance upon the glass transition of cuticula and lignin in the context of stronger inter-particle bonding. Indeed, as reported by Kaliyan et al., the binding forces between the particles can act through two main binding mechanisms, namely bonding with and without a solid bridge between particles. In this system, solid bridges can be formed between particles due to crystallization, chemical reactions, binder hardening, and solidification of melted components. In the absence of a solid bridge, molecular, electrostatic, and magnetic forces result in particle adhesion when the particles are in close proximity to one another (Kaliyan and Morey,
2010). A drastic variation of elongation and compression strength between $65^{\circ} \mathrm{C}$ and $100^{\circ} \mathrm{C}$, we therefore expect that reaching the glass transition of cuticula and lignin may form solid bridges between particles through crystallization and solidification of the melted components. Furthermore, upon removal of the cuticula, molecular, electrostatic, and magnetic forces can be present between particles, resulting in increased inter-particle bonding.

\subsection{Effect of Glass Transition Temperature on the Pellet Binding Mechanism}

To observe the binding mechanism and confirm the transition of mechanical properties during pellet formation, SEM images of the fractured pellets were taken after compression testing. Figs. 5a, 5c, and 5e show the surfaces of the fractured of raw sample pellets formed at 30, 65, and $100^{\circ} \mathrm{C}$, respectively, while and Figs. $5 \mathrm{~b}, 5 \mathrm{~d}$, and $5 \mathrm{f}$ show the surfaces of the extracted pellets formed at 30,65 , and $100^{\circ} \mathrm{C}$, respectively. Comparison of images a and c shows a reduced inter-particle gap, likely due to the glass transition of cuticula at the higher temperature. In addition, comparison of the extracted and raw samples formed at $30^{\circ} \mathrm{C}$ (Figs. $5 \mathrm{~b}$ and $5 \mathrm{a}$, respectively) showed a larger inter-particle gap for raw sample. This phenomenon indicates that the presence of cuticula on the miscanthus surface can act as a spacer between particles. When compared with images $\mathrm{c}$ and $\mathrm{d}$, reduced inter-particle spacing was observed due to the increased temperature and the resulting cuticula glass transition, along with increased 

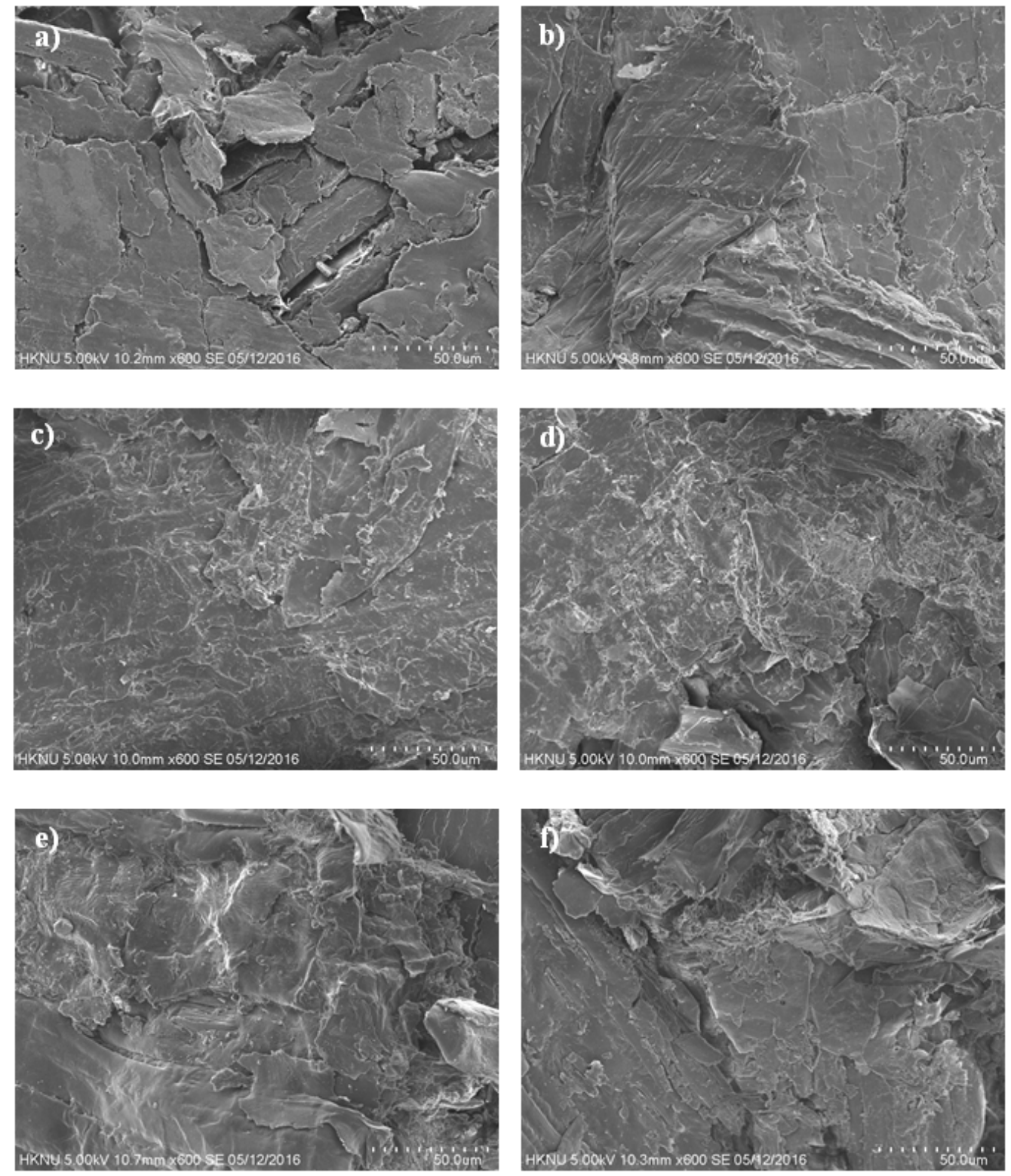

Fig. 5. SEM images of the fractured pellets after the compression test: Images a), c), and e) show the surfaces of the raw miscanthus pellets formed at 30,65 , and $100^{\circ} \mathrm{C}$, respectively. Images b), d), and f) show the surfaces of the extracted pellets formed at 30,65 , and $100^{\circ} \mathrm{C}$, respectively.

extraction. However, a smooth and densely interlocked surface is observed in image c, indicating that cuticula released from the mis- canthus surface during the glass transition can coat the particle surfaces, thus increasing the inter-particle distance. Furthermore, comparison 
with images $\mathrm{e}$ and $\mathrm{f}$ (i.e., particles formed at $100^{\circ} \mathrm{C}$ ) indicates the presence of a polymeric bridge that was not present in image $d$. This phenomenon could be accounted for by the formation of a lignin glassy state upon compression loading at this higher temperature, which resulted in the subsequent formation of polymeric bridges between particles upon cooling the pellet. Indeed, this polymeric lignin bridge affects the strength of inter-particle bonding and decreases the inter-particle distance, thus accounting for increase in pellet density and compression strength, as outlined in Fig. 4. Finally, comparison of the conditions from images $\mathrm{c}$ and $\mathrm{e}$ with the results outlined in Fig. 4 indicates that the higher density and compression strength of the raw sample resulted in the glass transition of lignin. However, the surface coating on the raw sample particles acted as a spacer between particles, thus deteriorating the mechanical properties of the pellet.

\subsection{Effect of Lignin as an Additive on the Pellet Mechanical Properties}

Use of lignin as an additive has been reported to improve the mechanical properties of pellets and decrease the production expenses (Berghel et al., 2013; Kulig et al., 2012; Kuokkanen et al., 2011; Lu et al., 2014; Tarasov et al., 2013). Moreover, lignin derived from the kraft pulping process has lower sulfur content than lignosulfonate, which is obtained as a by-product of sulfite cooking, and therefore, it is suitable for use in a combustion fuel
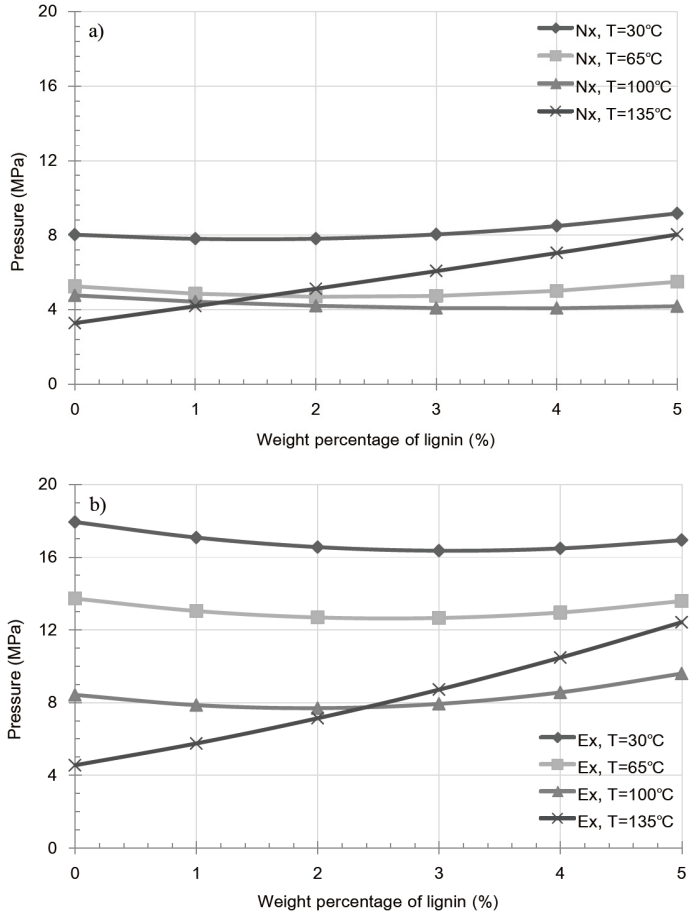

Fig. 6. Effect of lignin content and die temperature on friction for a) the raw miscanthus pellets, and b) the extracted miscanthus pellets.

(Vishtal and Kraslawski, 2011).

Fig. 6 shows the variation in pressure as a result of friction in the extracted and raw samples containing a lignin additive at various temperatures. As shown in Fig. 6a (raw samples), a large increase in friction is observed with increasing lignin content at $135^{\circ} \mathrm{C}$, while no significant effect was observed at 30,65 and $100^{\circ} \mathrm{C}$. In contrast Fig. 6b (extracted samples) shows a decrease in friction with increasing lignin content at 30,65 , and $100^{\circ} \mathrm{C}$. This indicates that kraft lignin acts as a lubricant in the inner die. Furthermore, in addition to the increase in friction observed in Fig. 6, a similar pattern was observed for both the extracted and raw 

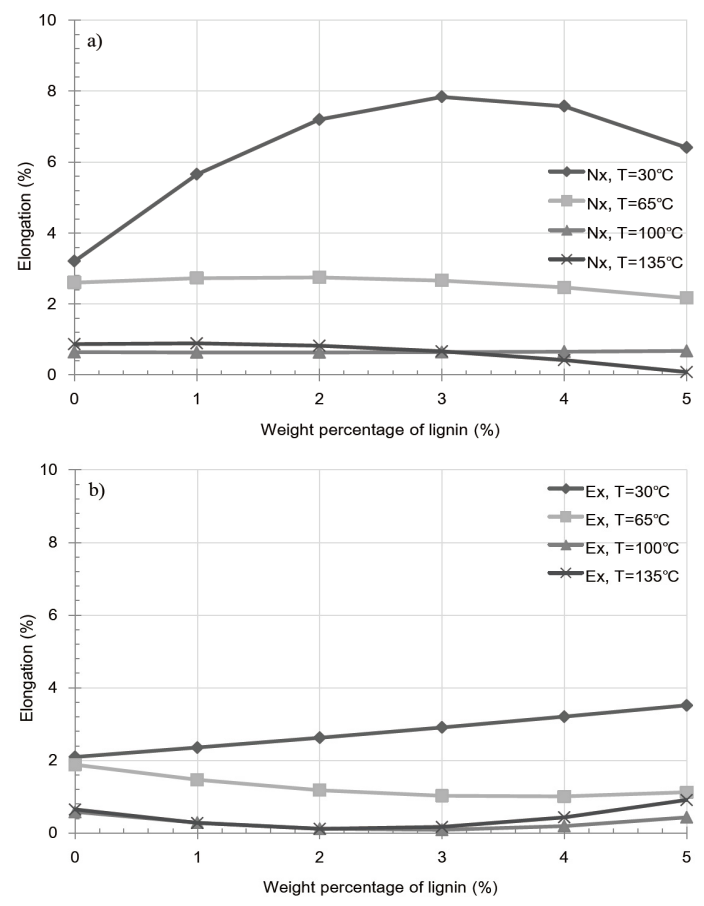

Fig. 7. Effect of lignin content and die temperature on elongation for a) the raw miscanthus pellets, and b) the extracted miscanthus pellets.

samples at $135^{\circ} \mathrm{C}$. This was the result of crack generation caused by the rapid evaporation of moisture and by the large temperature difference compared to those observed at atmospheric conditions. Such fractures were formed because of the failure of heterogeneous bonds between the particles, thus resulting in an increase in friction.

Fig. 7 shows the variation in pellet elongation after 1 week as a result of extracted and raw sample pellets containing a lignin additive at various temperatures. In both cases, a significant increase in elongation was observed at $30^{\circ} \mathrm{C}$, resulting from kraft lignin acting as an inhibitor to particle bonding, indicate that cuti-
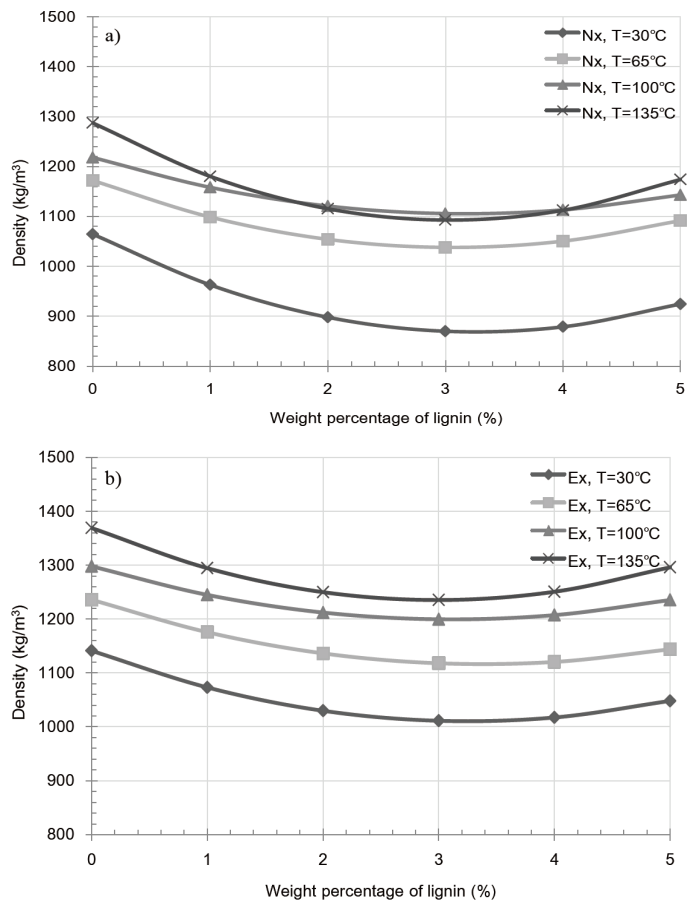

Fig. 8. Effect of lignin content and die temperature on pellet density for a) the raw miscanthus pellets, and b) the extracted miscanthus pellets.

cula present on the particle surfaces prevent to forming inter-particle bonding with kraft lignin additive. In contrast, at 65,100 and $135^{\circ} \mathrm{C}$, low elongation values were obtained, and either a decrease or little variation in elongation was observed for both types of pellet. Moreover, although the pellets had been shown to exhibit highly fractured surfaces at $135^{\circ} \mathrm{C}$, the extent of elongation remained low, indicating a strengthening of inter-particle bonds. The elongation decrease due to kraft lignin additive is expected to reduce bulk density as countervailing environmental effect.

Fig. 8 and 9 shows the variation in pellet density and compression strength caused by ex- 

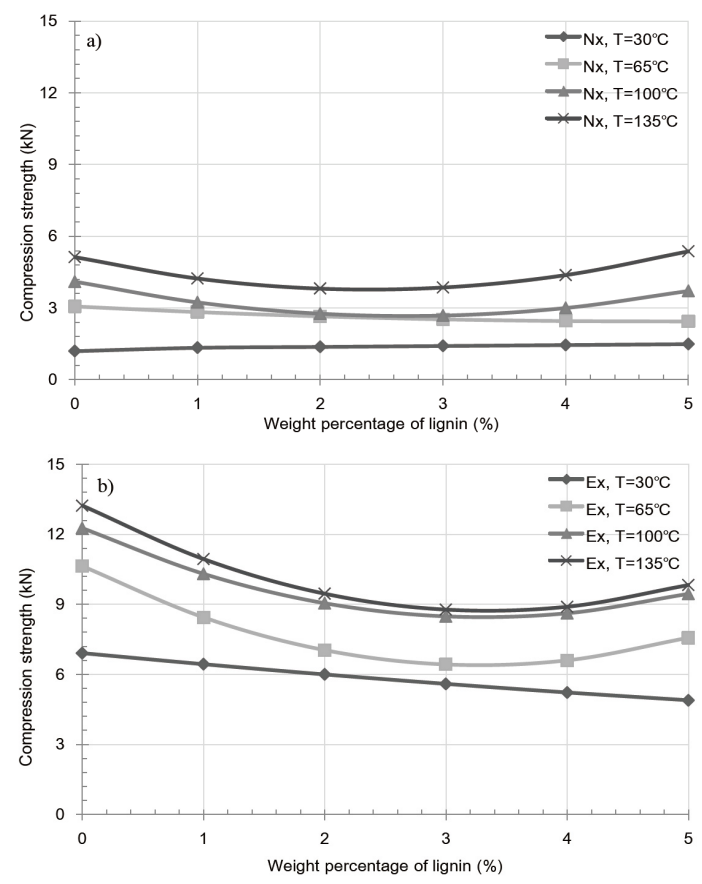

Fig. 9. Effect of lignin content and die temperature on compression strength for a) the raw miscanthus pellets, and b) the extracted miscanthus pellets.

tracted and raw samples containing a lignin additive at various temperatures. For both the extracted and raw samples, an overall decrease at 30 and $65^{\circ} \mathrm{C}$ was observed upon increasing the added kraft lignin content. This indicates an increase in the inter-particle distance and a decrease in inter-particle bonding, both of which result from the glass transition temperature and partial binding with miscanthus particle of the kraft lignin additive. Interestingly, the glass transition temperature of kraft lignin varies between 60 and $160^{\circ} \mathrm{C}$ and is dependent on the equilibrium moisture content derived from the relative humidity (Bouajila et al., 2006). Thus, the existent moisture contents of kraft lignin yield a high glass transition temperature, resulting in the formation of fractures, and as such, the additive fails to act as a binder between the inner particles of the pellet. Furthermore, Fig. 9a, 4-5 wt $\%$ lignin additive pellet at 100 and $135^{\circ} \mathrm{C}$ shows to slight increase of compression strength. However, in the majority of cases, the observed decrease in pellet density and compression strength for the both extracted and raw sample pellets at 100 and $135^{\circ} \mathrm{C}$ was due to the formation of fractures in miscanthus pellet. This phenomenon indicates that kraft lignin additive result in weak bonding with miscanthus regardless of extract condition.

\section{CONCLUSION}

In the context of Miscanthus sacchariflorus "Goedae-Uksae1" (miscanthus), this cultivar has lower carbohydrate content than do other herbaceous crops, but its high glucose fraction renders it a possible energy crop. In addition, Goedae-Uksae1 also contains $19.5 \%$ lignin, which is significantly higher than the levels present in other miscanthus cultivar, resulting in positive effect on combustion. However, we found that cuticula acts as a lubricant to decrease friction between the inner die used in pellet production and the miscanthus particles themselves, but has a detrimental effect on the mechanical properties of the pellet. Thus, the removal of cuticula through ethanol extractions improved the mechanical properties of the pellet by the formation of strong inter-particle interactions. Furthermore, we also determined 
that the presence of lignin in miscanthus improves its mechanical properties and decreases friction against the inner die at temperatures above the glass transition temperature $\left(\mathrm{T}_{\mathrm{g}}\right)$ of lignin. Consequently, we investigated the use of kraft lignin as an additive in pellet, and observed that it reduced friction in the inner die upon reaching its glass transition temperature. In addition, it contributed to deterioration in the mechanical properties of the pellets due to the low moisture content of kraft lignin. However, low elongation values were obtained, and either a decrease or little variation in elongation was observed for both types of lignin additive pellet.

\section{ACKNOWLEDGEMENTS}

This work was supported by the New \& Renewable Energy Core Technology program of the Korea Institute of Energy Technology Evaluation and Planning (KETEP) granted financial resource from the Ministry of Trade, Industry \& Energy, Republic of Korea (Grant \# : 20153030101470). This work was also supported by Interagency Convergence Energy on New Biomass Industry, Hankyong National University.

\section{REFERENCES}

Berghel, J., Frodeson, S., Granström, K., Renström, R., Ståhl, M., Nordgren, D., Tomani, P. 2008. The effects of kraft lignin additives on wood fuel pellet quality, energy use and shelf life. Fuel Processing Technology 112: 64 69.

Bouajila, J., Dole, P., Joly, C., Limare, A. 2006. Some laws of a lignin plasticization, Journal of
Applied Polymer Science 102(2): 1445 1451. Brosse, N., Meng, X., Sun, Q., Ragauskas, A. 2012. Miscanthus: a fast-growing crop for biofuels and chemicals production, Biofuels. Bioproducts, and Biorefining 6(5): 580 598.

Buranov, A.U., Mazza, G. 2008. Lignin in straw of herbaceous crops. Industrial Crops and Products 28(3): $237 \sim 259$.

Dubis, E.N., Dubis, A.T., Popławski, J. 2001. Determination of the aromatic compounds in plant cuticular waxes using FT-IR spectroscopy, Journal of Molecular Structure 596(1-3): 83 88,

Ibarra, D., Río, J.C.d., Gutiérrez, A., Rodríguez, I.M., Romero, J., Martínez, M.a.J., Martínez, Á.T. 2004. Isolation of high-purity residual lignins from eucalypt paper pulps by cellulase and proteinase treatments followed by solvent extraction. Enzyme and Microbial Technology 35(2-3): $173 \sim 181$.

Jurišić, V., Bilandžija, N., Krička, T., Leto, J., Matin, A., Kuže, I. 2014. Fuel properties' comparison of allochthonous Miscanthus $\mathrm{x}$ giganteus and autochthonous Arundo donax L.: a study case in Croatia. Agriculturae Conspectus Scientificus (ACS) 79(1): 7 11.

Kaliyan, N., Morey, R.V. 2009. Factors affecting strength and durability of densified biomass products. Biomass and bioenergy 33(3): 337 359.

Kaliyan, N., Morey, R.V. 2010. Natural binders and solid bridge type binding mechanisms in briquettes and pellets made from corn stover and switchgrass. Bioresource Technology 101(3): 1082 1090.

Kaltschmitt, M., Reinhardt, G., Stelzer, T. 1997. Life cycle analysis of biofuels under different environmental aspects. Biomass and Bioenergy 12(2): $121 \sim 134$.

Kulig, R., Skonecki, S., Lysiak, G. 2012. The effect 
of binder addition on the parameters of compacted poplar wood sawdust. Teka Komisji Motoryzacji i Energetyki Rolnictwa 12(1): 303 $\sim 309$.

Kuokkanen, M.J., Vilppo, T., Kuokkanen, T., Stoor, T., Niinimäki, J. 2011. Additives in wood pellet production-a pilot-scale study of binding agent usage. BioResources 6(4): 4331 4355.

Lu, D., Tabil, L.G., Wang, D., Wang, G., Emami, S. 2014. Experimental trials to make wheat straw pellets with wood residue and binders. Biomass and Bioenergy 69: 287 296.

Mani, S., Tabil, L.G., Sokhansanj, S. 2006. Effects of compressive force, particle size and moisture content on mechanical properties of biomass pellets from grasses. Biomass and Bioenergy 30(7): $648 \sim 654$.

Merk, S., Blume, A., Riederer, M. 1997. Phase behaviour and crystallinity of plant cuticular waxes studied by Fourier transform infrared spectroscopy. Planta 204(1): 44 53.

Moon, Y., Koo, B., Choi, Y., Ahn, S., Bark, S., Cha, Y., An, G., Kim, J., Suh, S. 2010. Development of Miscanthus the Promising Bioenergy Crop. Korean Journal of Weed Science 30(4): 330 339.

Nguyen, Q.N., Cloutier, A., Achim, A., Stevanovic, T. 2015. Effect of process parameters and raw material characteristics on physical and mechanical properties of wood pellets made from sugar maple particles. Biomass and Bioenergy 80: 338 $\sim 349$.

Nielsen, N.P.K., Gardner, D.J., Poulsen, T., Felby, C. 2009. Importance of temperature, moisture content, and species for the conversion process of wood residues into fuel pellets. Wood and Fiber Science 41(4): 414 425.

Nilsson, D., Bernesson, S., Hansson, P.-A. 2011. Pellet production from agricultural raw materialsA systems study. Biomass and Bioenergy 35(1):
$679 \sim 689$.

Park, S.J., Moon, J.K., Um, B.H. 2013. Evaluation of the efficiency of solvent systems to remove acetic acid derived from pre-pulping extraction. Journal of the korean wood Science and Technology 41(5): 447 455.

Rabier, F., Temmerman, M., Bohm, T., Hartmann, H., Daugbjergjensen, P., Rathbauer, J., Carrasco, J., Fernandez, M. 2006. Particle density determination of pellets and briquettes. Biomass and Bioenergy 30(11): 954 963.

Rentizelas, A.A., Tolis, A.J., Tatsiopoulos, I.P., Logistics issues of biomass: the storage problem and the multi-biomass supply chain. Renewable and Sustainable Energy Reviews 13(4): 887 894.

Serrano, C., Monedero, E., Lapuerta, M., Portero, H. 2011. Effect of moisture content, particle size and pine addition on quality parameters of barley straw pellets. Fuel Processing Technology 92(3): 699 706.

Sikkema, R., Junginger, M., Pichler, W., Hayes, S., Faaij, A.P. 2010. The international logistics of wood pellets for heating and power production in Europe: Costs, energy-input and greenhouse gas balances of pellet consumption in Italy, Sweden and the Netherlands. Biofuels, Bioproducts and Biorefining 4(2): 132 153.

Sluiter, A., Hames, B., Ruiz, R., Scarlata, C., Sluiter, J., Templeton, D., Crocker, D. 2008. Determination of structural carbohydrates and lignin in biomass. (NREL/TP-510-42619), National Renewable Energy Laboratory.

Sluiter, A., Ruiz, R., Scarlata, C., Sluiter, J., Templeton, D. 2008. Determination of extractives in biomass (NREL/TP-510-42619), National Renewable Energy Laboratory.

Stelte, W., Clemons, C., Holm, J.K., Ahrenfeldt, J., Henriksen, U.B., Sanadi, A.R. 2012. Fuel pellets 
Effect of Process Parameters and Kraft Lignin Additive on The Mechanical Properties of Miscanthus Pellets

from wheat straw: The effect of lignin glass transition and surface waxes on pelletizing properties. BioEnergy Research 5(2): 450 458. Stelte, W., Clemons, C., Holm, J.K., Ahrenfeldt, J., Henriksen, U.B., Sanadi, A.R. 2011. Thermal transitions of the amorphous polymers in wheat straw. Industrial Crops and Products 34(1): 1053 $\sim 1056$.

Tarasov, D., Shahi, C., Leitch, M. 2013. Effect of Additives on Wood Pellet Physical and Thermal Characteristics: A Review. ISRN Forestry. 1 6. Tumuluru, J.S., Sokhansanj, S., Lim, C.J., Bi, T., Lau, A., Melin, S., Sowlati, T., Oveisi, E. 2010. Quality of wood pellets produced in British Columbia for export. Applied Engineering in
Agriculture 26(6): 1013 1020.

Vassilev, S.V., Baxter, D., Andersen, L.K., Vassileva, C.G. 2010. An overview of the chemical composition of biomass. Fuel 89(5): $913 \sim$ 933.

Villaverde, J.J., Domingues, R.M.A., Freire, C.S.R., Silvestre, A.J.D., Neto, C.P., Ligero, P., Vega, A. 2009. Miscanthus $\mathrm{x}$ giganteus Extractives: A Source of Valuable Phenolic Compounds and Sterols. Journal of Agricultural and Food Chemistry 57(9): 3626 3631.

Vishtal, A.G., Kraslawski, A. 2011. Challenges in industrial applications of technical lignins. BioResources 6(3): 3547 3568. 